ENSAYO

\title{
LOS EMBRUJOS DEL QUIJOTE
}

\author{
Howard Mancing
}

La película intitulada "El embrujo del Quijote" presenta una nueva teoría sobre la autoría del Quijote. Partiendo del pretexto de esta película, Howard Mancing emprende un resumen histórico de obras literarias en las que también hay unas "teorías" originales al respecto, esto es, otros "embrujos" del Quijote. Resulta que Cervantes mismo fue el primero en sugerir que él no es el autor de la obra, llamándose "padrastro" y presentando a Cide Hamete Benengeli como autor, o "padre", de la historia de don Quijote y Sancho Panza. La novela como género literario, se sostiene en este artículo, siempre ha consistido en este tipo de juego metaficticio.

Howard MANCING se doctoró en la Universidad de Florida en 1970. Ha sido profesor de literatura española en Lycoming College y las Universidades de Missouri y Purdue. Es el autor de The Chivalric World of Don Quijote (1982), The Cervantes Encyclopedia (2 vols., 2004), y Miguel de Cervantes's "Don Quixote": A Reference Guide (sale en 2006), y con su colega Charles Ganelin ha editado Text, Theory, and Performance: Golden Age Comedia Studies (1994). Ha escrito también más de cuarenta artículos y ensayos sobre Cervantes, la novela picaresca, la teoría narrativa, y otros temas. En los últimos años se ha interesado en las relaciones entre la teoría literaria y la ciencia cognitiva, y actualmente está escribiendo un libro que lleva el título tentativo de Literary Theory in Context: Linguistics, Biology, and Psychology (La teoria literaria en contexto: Lingüistica, psicología, y biología).

Estudios Públicos, 100 (primavera 2005). 


\section{El embrujo del Quijote}

"E embrujo del Quijote" es el título de una película que se está rodando ahora mismo en España, dirigida por Chumilla Carbajosa y protagonizada por el distinguido actor Rafael Álvarez, "El Brujo" (el título de la película es, entre otras cosas, un juego de palabras con el sobrenombre del actor protagonista). Se basa en una obra teatral estrenada el 15 de julio de 2005 durante el festival de teatro de Almagro con el título "Los Misterios del Quijote, o, El ingenioso caballero de la palabra", un monólogo de más de dos horas de "El Brujo". Entre comentarios satíricos sobre todo lo que está pasando este año durante el IV centenario del Quijote, recuerdos personales, anécdotas y chistes, "El Brujo" presenta una nueva teoría sobre la autoría de la novela. Según esta teoría, nunca existió Miguel de Cervantes, y la creación de la obra se debe a un grupo de místicos musulmanes que la escribieron durante la primera mitad del siglo XVI. El texto del Quijote sería cabalístico y en su totalidad supondría una alegoría de amor y armonía religiosa. El rodaje tendrá lugar en Madrid, en varios sitios de La Mancha, en el norte de África, y tal vez hasta en Estados Unidos.

Aunque pueda parecer atrevido inventar una nueva génesis del Quijote, la verdad es que nos encontramos sólo ante la obra más reciente de una larga serie de teorías esotéricas sobre los orígenes de la novela de Cervantes. En otras palabras, éste no es el primer "embrujo" del Quijote, y en este ensayo quiero esbozar brevemente una historia de tales lecturas esotéricas. En efecto, toda la historia del Quijote, junto a la del cervantismo, puede considerarse un gran "embrujo".

\section{Los embrujos del Quijote}

En primer lugar, quiero dejar claro que cuando me refiero a "lecturas esotéricas" de la novela de Cervantes, no estoy pensando en esa larga y bien conocida serie de ensayos en los que se han propuesto unas disparatadas lecturas del Quijote y/o de su autor: Cervantes era homosexual, era judío, era de la región de Sanabria; Cervantes es el autor del Quijote de Avellaneda; el Quijote está lleno de símbolos, anagramas y nombres secretos; es una autobiografía alegórica de Cervantes; es una alegoría política del reinado de Felipe II, del duque de Lerma, de Medina Sidonia; es un monumento de literatura cristiana; es una severa crítica de la Inquisición y un clero corrupto; es un texto cabalístico judío; la novela fue escrita no por 
Cervantes sino por El Greco, o por Francis Bacon (autor también de todas las obras de Shakespeare) ${ }^{1}$.

Lo que me interesa en este ensayo son unas obras literarias originales en las que se propone una génesis nueva (y ficticia) para la concepción y la escritura de la novela. En ellas siempre se apunta una teoría según la cual Cervantes no es el autor originario de la idea, o del concepto, de la historia de don Quijote. La gran mayoría de estas obras datan de la segunda mitad del siglo XX o principios del XXI y se han escrito con plena conciencia del postmodernismo y de la metaficción. Sobre todo quiero destacar a ocho ingeniosos escritores - dos españoles, dos argentinos, un colombiano, un norteamericano, un portugués y un sudafricano- que han propuesto sus propios embrujos del Quijote ${ }^{2}$.

El primero, y uno de los más fascinantes, es un relato muy corto de 1966 del cuentista argentino Mario Denevi que lleva por título "El precursor de Cervantes" (publicado en su libro Falsificaciones). Se trata del descubrimiento en los archivos de la Universidad de Alcalá de Henares de un manuscrito fechado en 1563. El manuscrito es en general de poco interés, pero con una excepción: se trata de un breve fragmento en el que se describe a una mujer que vivía en el Toboso, llamada Aldonza Lorenzo. Esta joven leía muchos libros de caballerías, enloqueció, dio en llamarse Dulcinea del Toboso, insistió en que todo el mundo la tratara como a una gran dama, se creía hermosa (no lo era), inventó a un caballero andante a quien dio el nombre de don Quijote, y pasó sus días esperando su llegada. Mientras tanto, un hidalgo de un lugar cercano, que se había enamorado de Aldonza, decidió hacerse su don Quijote, adoptó este nombre, y salió en busca de aventuras caballerescas. Cuando llegó a creer que había ganado bastante fama para merecer la mano de su dama, volvió - y se enteró de que durante su ausencia ella había fallecido. Lo que no dice Denevi, pero queda implícito en su cuento, es que hay una base histórica para lo que pasa en la novela, que Cervantes se inspiró en esta historia (y que la cambió radicalmente) para escribir el Quijote, pero la idea original no era suya. Podemos considerar "El precursor de Cervantes" de Mario Denevi —un escritor fascinado por el Quijote, que ha escrito múltiples variaciones sobre sus temas - como el prototipo de los embrujos del Quijote.

${ }^{1}$ Para un resumen de estas teorías esotéricas y comentario sobre sus autores, véanse Howard Mancing, "Esoteric Readings", en H. Mancing, The Cervantes Encyclopedia (Wesport, CT: Greenwood Press, 2004), vol. I, pp. 271-72; y Ascención Rivas Hernández, Lecturas del Quijote (Siglos XVII-XIX) (Ediciones Colegio de España), pp. 29-31, 171-241.

${ }^{2}$ Para evitar excesiva documentación remito al lector a Howard Mancing, Cervantes Encyclopedia, 2 vols., op. cit., para más datos sobre los autores y las obras citadas en este ensayo. Sin embargo, cuando se cita a un autor que no se incluye en esta Encyclopedia se da la documentación completa. 
Pedro Gómez Valderrama, diplomático y escritor colombiano, que ha dicho más de una vez que Cervantes era su "maestro," es el autor de un cuento titulado "En un lugar de las Indias" (1970; incluido en su libro La procesión de los ardientes, 1973). Se trata de una historia que escribe Alonso Quijano sobre un ex-soldado español llamado Miguel de Cervantes que solicita y recibe permiso para tomar un cargo administrativo en las Indias. Al mismo tiempo que la petición es concedida, otra del mismo Quijano es rechazada. La mujer de Cervantes, Doña Catalina, decide quedarse en Esquivias en vez de emigrar al Nuevo Mundo, de modo que Cervantes llega solo a América. Poco después, toma como amante a una mulata llamada Piedad a la vez que se enfrenta al alcoholismo y la depresión. Cuando muere Cervantes, se descubre que desde hacía tiempo escribía un largo manuscrito, pero Piedad ha usado los folios para hacer fuego y calentar la casa. En este cuento genial, una de las mejores ficciones cortas quijotescas, autor y personaje cambian de papeles, y el Quijote nunca llega a escribirse.

El psicoanalista y escritor argentino Nasim Yampey es el autor de una obra titulada Mocedades de Alonso Quijano, el bueno (1985), una versión ficticia de la juventud de Alonso Quijano. Durante su juventud llega Alonso a conocer y a hablar con varias personas que más tarde van a aparecer en el Quijote: el pastor Paco Zancas, una prostituta llamada Zoraida, Altisidora, y otros muchos. Su hermano Miguel le manda una carta en la que describe la vida militar en Italia y lo que pasó en la batalla de Lepanto. Un día el joven Cervantes interrumpe una comedia en defensa de la inocencia (que anticipa el retablo de Maese Pedro), ve molinos de viento que parecen ser gigantes, aprende a preparar un brebaje salutífero de vino, aceite y romero (el bálsamo de Fierabrás), y mucho más. En el último capítulo, tiene un sueño en el que le visita Miguel de Cervantes / Hamid Berenjena que le describen su futuro y la novela sobre don Quijote que algún día escribirá. Aquí Cervantes sí que es el autor del Quijote, pero no inventa casi nada.

El próximo escritor que quiero mencionar ha propuesto una de las teorías más elaboradas y geniales de la génesis del Quijote. Se trata del muy respetado novelista norteamericano Paul Auster y de su novela City of Glass (1985; Ciudad de cristal), primer tomo de su Trilogía de Nueva York. La trama de la novela es demasiado complicada para resumirla aquí, pero en una escena clave, el protagonista y novelista Daniel Quinn (nótense las iniciales: DQ), conoce al también narrador Paul Auster y los dos discuten acerca del Quijote. Auster propone la siguiente ingeniosa y complicada teoría: que 1) la historia de don Quijote y Sancho Panza fue dictada por Sancho al cura Pero Pérez y al barbero Maese Nicolás; 2) éstos la llevaron a Sansón Carrasco quien la escribió en árabe; y 3) esta versión es el manus- 
crito que compró Miguel de Cervantes en Toledo, donde buscó a un morisco aljamiado a quien pagó para traducirlo de nuevo al español. Pero hay más: 4) el hecho es que todo esto era una traza concebida por don Quijote mismo, quien se disfrazó de morisco, siendo el hombre que empleó Cervantes para traducir el manuscrito árabe al español. Aquí Cervantes no es más que un peón, de los muchos manipulados por don Quijote en un gran juego de ajedrez literario. La novela de Auster es genial, una metaficción en más de un nivel que explora los temas de la creación literaria, la identidad y la locura. Y es uno de los embrujos más complicados y más sofisticados del Quijote.

Luis Enrique Tord es un antropólogo, poeta y cuentista peruano. Su magistral cuento titulado "Cide Hamete Benengeli, coautor del Quijote" ganó un concurso literario en 1987. El cuento se presenta como un comentario erudito sobre un viejo manuscrito descubierto en un monasterio peruano. El autor del manuscrito es un cierto Fray Diego de la Santa Fe, franciscano, que describe cómo en su juventud, cuando todavía se llamaba Antón Gonzálvez, fue encarcelado un tiempo en la prisión de Sevilla en el año 1602 por motivo de ciertas prácticas religiosas sospechosas. En la cárcel conoció a un ex-soldado manco que se llamaba Miguel de Cervantes, un hombre que conocía muy bien la cultura y la religión musulmanas y que tenía un gran interés en el misticismo sufí. Este compañero pensaba escribir algún día la historia de un personaje que representara los intereses sufíes sobre la relación entre la realidad y la apariencia, y Gonzálvez le entretuvo con cuentos alegóricos que hacía años le había contado un tío suyo. Resulta que este Gonzálvez era de herencia morisca, algo que trataba de encubrir ante las autoridades, y su nombre original era Hamete ben Gelie. Años más tarde, en 1620, fraile ya, encontró una copia del Quijote en el monasterio y se dio cuenta de que Cervantes había usado sus conversaciones para crear tanto a su protagonista como a su narrador. Él, Antón Gonzálvez - Hamete ben Gelie-, era, en efecto, co-autor del Quijote. En este embrujo, el Quijote se concibió en una cárcel, tal como relata Cervantes en el prólogo de la primera parte, pero bajo circunstancias muy distintas de las implícitas en sus palabras. El cuento de Luis Enrique Tord es una joya.

El distinguido novelista portugués António Lobo Antunes ha escrito en As naus (1988; Las naves) una impresionante mezcla de historia y realismo contemporáneo, yuxtaponiendo los restos del pasado glorioso de su país con el tema contemporáneo del colapso del concepto de imperio. En el puerto de Lisboa se entremezclan galeras renacentistas con grandes vapores de transporte, al mismo tiempo que se cruzan historias de personajes de distintos siglos. En unas escenas cómicas de la primera parte de la novela se menciona brevemente a un español manco que se llama Cervantes, ex- 
soldado y, más recientemente, vendedor de billetes de lotería en Mozambique, que está siempre escribiendo trozos de un relato titulado Quijote (nadie sabe por qué lleva este título; es el nombre de un famoso caballo de carreras). Este Cervantes habla con frecuencia de una tal Dulcinea del Toboso, de unos molinos de viento, y de otros disparates. Aquí Cervantes es el autor de la novela, pero la ha escrito en circunstancias muy distintas de las que sabemos, al igual que este Cervantes es muy diferente del hombre histórico que conocemos.

Carlos Ansó, dramaturgo español, escribió su comedia Don Quijote, o el sueño de Cervantes, en italiano en el año 1995 y luego la tradujo al español en 1998. Los dos actos de la obra corresponden más o menos a las dos partes del Quijote y la acción tiene lugar dentro, o cerca, de la casa de Cervantes, donde vive el escritor con su mujer Catalina y su hija natural Isabel. Mientras Cervantes está agonizando sobre la creación del Quijote, le visitan don Quijote y Sancho y hay una serie de incongruas conversaciones. Los personajes toman y abandonan varios papeles de la novela: Catalina e Isabel quieren quemar los libros de Cervantes; don Quijote cavila sobre cuál de estas mujeres debe tomar como su dama; Catalina aconseja a Cervantes de qué manera ha de escribir el prólogo de la primera parte; Cervantes se viste de moro para espiar a don Quijote y Sancho, apuntando sus acciones para reproducirlas en su libro; Catalina e Isabel presentan el retablo de Gaiferos y Melisendra; don Quijote muere en casa de Cervantes, rodeado de su autor y la familia de éste. Una de las obras teatrales más interesantes basadas en el Quijote, este "sueño de Cervantes" nos presenta al autor, a su familia, y a sus personajes en un conjunto donde se borran por completo las fronteras entre vida y ficción, autor y personaje, apariencia y realidad.

Julian Branston, novelista sudafricano, ha logrado un gran éxito editorial con su novela The Eternal Quest (2003; La búsqueda eterna, publicada también en 2005 con el título Tilting at Windmills -Arremeter contra molinos de viento $)^{3}$. La novela tiene su interés, pero Branston no es capaz de evocar el Siglo de Oro español (a pesar de los elogios a la novela por parte de algunos lectores angloparlantes) y ha escrito una obra francamente tonta. Sin embargo, lo mejor de la novela, que se ubica en Valladolid en los primeros años del siglo XVII, tiene que ver con la génesis del Quijote. Miguel de Cervantes está ganando mucha popularidad con las entregas de sus historias cómicas sobre el personaje de don Quijote. Pero empiezan a ocurrir una serie de eventos inesperados. Primero, un hombre que se conoce sencillamente como "el viejo caballero" y que se llama "Don Lanzarote", comienza a portarse como una versión real del héroe cervantino, tomando

${ }^{3}$ Julian Branston, The Eternal Quest (London: Scepter, 2003). 
una yegua vieja como caballo y llamándola Bucéfalo, usando una cazuela no para yelmo sino para espada, etc. Un día sorprenden a Cervantes diciéndole que el personaje que ha inventado existe de veras y que Cervantes le ha pintado exactamente tal como es en realidad: "el auténtico Quijote, el vivo, ... el hijo de tus obras" (traducción mía). Por un momento el narrador contempla lo que pasaría si un personaje ficticio lograra salir de su historia para entrar en el mundo real: ¿no sería peligroso? Más tarde, otro personaje le comenta a Cervantes que si los personajes insisten en su derecho de existir fuera de los libros será necesario construirles un nuevo pueblo $-\mathrm{y}$ llamarlo Imaginápolis. De nuevo, aquí tenemos una mezcla de realidad y ficción, una abolición de fronteras entre un nivel ontológico y otro, y un Cervantes que a veces no sabe lo que está escribiendo.

Estas ocho obras son buenos ejemplos de este juego metaficticio que he llamado "embrujos" del Quijote. Pero hay docenas de otras obras de este tipo, obras en las cuales abundan - aunque de una manera menos complicada o no tan directamente relacionada con la cuestión de la autoría de la novela de Cervantes- juegos análogos. En vez de desarrollar en algún detalle estos juegos literarios, estos embrujos, me limito a citar e indicar en una breve frase lo que más nos interesa en este aspecto ${ }^{4}$. Como veremos, ya siglos antes del llamado postmodernismo hay autores ingeniosos que crean sus propios embrujos y que emplean unas técnicas que solemos asociar con la literatura contemporánea. He aquí, en orden cronológico, un listado de embrujos quijotescos:

- en su novela Adiciones a la historia del ingenioso hidalgo Don Quixote de la Mancha (1786), Jacinto María Delgado describe lo que le pasa a Sancho después de la muerte de su amo y —lo que es de más interés para nosotros- termina el libro con un apéndice en el que el escritor árabe Melique Zulema nos informa de la vida y muerte del hombre de carne y hueso que era Cide Hamete Benengeli;

- en La moral de Don Quixote deducida de la historia que de sus gloriosas hazañas escribió Cide Hamete Benengeli. Por su grande Amigo el Cura. Dala a luz el Br. D. P. Gatell (2 tomos, 1789, 1792), de Pedro Gatell, se presenta un texto supuestamente escrito por el cura Pero Pérez, que el autor adquirió de un boticario;

- en Cervantes de levita. Nuestros libros de caballería (1905), de Eduardo Barriobero y Herrán, Cervantes, que vuelve a vivir a principios del siglo XX, no logra interesar a nadie con su obra y muere sin poder publicar el Quijote;

${ }^{4}$ Otra vez remito al lector a Howard Mancing, The Cervantes Encyclopedia, 2 vols., op. cit., para más datos sobre todos estos escritores y sus obras. 
- en "The Last Adventure of Don Quixote" (1917; "La última aventura de Don Quijote", incluido en The Secret Mountain and Other Tales (1926; La montaña secreta y otros cuentos) el escritor galés Kenneth Morris presenta una obra traducida de un manuscrito de Cide Hamete Benengeli en el que don Quijote no muere, como en el último capítulo de la novela cervantina, sino que recupera su salud y vuelve a salir en busca de aventuras, pero esta vez en compañía del Arcángel Miguel;

- en el curioso libro El nieto de Don Quijote (1918), el humorista español Luis Esteso y López de Haro, se escribe que, antes de morir en el pueblo manchego de San Clemente, don Quijote se casó con Dulcinea y que tuvieron un hijo, padre del narrador de estas aventuras autobiográficas;

- en su breve parábola titulada "Die Wahrheit über Sancho Panza" ("La verdad sobre Sancho Panza") de Franz Kafka, e incluido en su libro de cuentos Beim bau der chinesischen mauer (1931; La gran muralla de China), es Sancho quien en un sueño inventa a don Quijote;

- en su famoso cuento "Pierre Menard, autor del Quijote" (1941; en Ficciones), Jorge Luis Borges describe cómo un poeta francés escribe (una parte de) el Quijote en el siglo XX;

- en el Primer libro de Sendas de Olvido o Don Quijote en tierras leridanas (1944) el escritor catalán J. Salat Fornells presenta, a base (otra vez) de un manuscrito de Cide Hamete Benengeli, las aventuras de don Quijote y Sancho en Lérida, y en una escena un personaje le explica al caballero andante que aunque se atribuye la primera parte de sus aventuras a Cide Hamete, el verdadero autor es Miguel de Cervantes;

- en su comedia de un acto titulado Don Quixote de la Mancha (1973), Brainerd Duffield presenta a algunos personajes y algunas escenas del Quijote, pero durante toda la obra, Cervantes está sentado al lado del escenario, comentando lo que pasa en un diálogo con el público;

- en la última parte del cuento "Las brasas del libro", que el argentino Federico Peltzer incluye en su libro Un país y otro país (1976), se describe el hallazgo de un nuevo manuscrito de Cide Hamete Benengeli que incluye un episodio que tuvo lugar durante la vuelta de don Quijote y Sancho de Barcelona a su aldea en el cual escudero y caballero cambian papeles durante cierto tiempo;

- en el cuento Las bodas de Don Quijote (1978), el novelista mexicano Agustín Yáñez describe cómo, después de recuperar su salud, don Quijote decide casarse con Aldonza, y aunque Cervantes se opone a la idea, lo hace, pero resulta que el matrimonio no es feliz y al final don Quijote vuelve a soñar con su Dulcinea;

- en la hermosa novela The Duchess's Diary (1980; El diario de la duque$s a$ ), el escritor inglés Robin Chapman describe cómo Cervantes, tras 
publicar la primera parte de su novela, visita el castillo de los duques donde, para entretenerse, se preparan una serie de escenas cómicas que el novelista luego incorpora en su segunda parte;

- en su libro Los nacimientos (1982), el uruguayo Eduardo Galeano evoca momentos importantes en la historia de Hispanoamérica; en uno, titulado sencillamente "Cervantes", Sancho informa a don Quijote de la muerte de su "padre", Cervantes, y el caballero decide honrar a su creador buscando nuevas aventuras en las Indias;

- en la comedia El viaje infinito de Sancho Panza (1984), Alfonso Sastre nos presenta a un Sancho loco, encerrado en un manicomio, que critica el Quijote de Miguel de Cerpontes (o Cervantes; no está claro) y explica cómo era él, Sancho, ávido lector de los libros de caballerías, quien inspiró a don Quijote a salir en busca de aventuras y todo lo que pasó;

- en su novela Tidewater Tales (1987; Cuentos de la marea), el novelista norteamericano John Barth describe a un don Quijote que, en una serie de barcos llamados todos "Rocinante", sale de la novela y de Europa y está ya en el siglo XX, y bajo el nombre de Capn Quicksoat, marinero en un barco (Rocinante IV) en la Bahía de Chesepeake;

- en la extravagante novela de ciencia ficción del profesor norteamericano James McConkey, titulada Kayo, the Authentic and Annotated Autobiographical Novel from Outer Space (1987; Kayo, la auténtica y anotada novela autobiográfica del espacio exterior), un profesor norteamericano, cuyo libro favorito es el Quijote, recibe telepáticamente de otro planeta la narrativa autobiográfica de la vida de cierto Kayo, u Ohcnas Aznap (Kayo = OK, de Ohc; Ohcnas Aznap = Sancho Panza) y sus auténticas aventuras con Nod (Nod = Don [Quijote]) y Kayo le da el nombre de $\mathrm{Sid}$ (Sid = Cide [Hamete Benengeli]) de su narrador terráqueo;

- en la genial The Death and Life of Miguel de Cervantes: A Novel (1991; Muerte y vida de Miguel de Cervantes: Novela), el novelista norteamericano Stephen Marlowe evoca la vida de Cervantes, empezando por su cautiverio en Argel, donde conoce a gente como Cide Hamete Benengeli, un ráwi (un narrador árabe de historias orales), su amante Zoraida, y a muchos más;

- en su cuento "The Resurrection of Alonso Quijana" (1992; "La resurrección de Alonso Quijana"), el escritor norteamericano de ciencia ficción Marcos Donnelly presenta lo que es supuestamente una serie de seis suplementos al capítulo final del Quijote donde se explica cómo Alonso Quijano sueña que se encuentra en la Arabia Saudí en el año 1981, durante la Guerra del Golfo, y lo que le pasó allá;

- y, finalmente, en un cuento titulado "Donde se trata de la accidentada visita de Don Quijote y su escudero a una ciudad embrujada" (1996; en 
El reloj maldito), el escritor costarricense Alfonso Chacón Rodríguez describe un fragmento del manuscrito de Cide Hamete Benengeli, que puede ser apócrifo, en el que don Quijote y Sancho visitan una ciudad moderna.

Se ve cómo ciertos temas predominan en estas obras. Sobre todo, la enigmática figura de Cide Hamete Benengeli es de primerísima importancia. Si Cervantes escribe que ha encontrado y ha hecho traducir el manuscrito original de Cide Hamete, otros autores cervantinos fingen haber encontrado un nuevo capítulo de la obra benengeliana, o un nuevo manuscrito suyo. El supuesto historiador árabe no desapareció con la obra de Cervantes, sino que ha tenido una vida muy activa en los últimos 400 años.

\section{El primer embrujo del Quijote}

No debe sorprendernos la existencia de esta larga tradición de embrujos quijotescos, dado que el primero de la serie data del año 1605 y el autor es Miguel de Cervantes. Uno de los hechos asombrosos del Quijote es que Cervantes anticipa casi todo lo que llamamos el postmodernismo con respecto a la técnica narrativa. La narrativa postmoderna se jacta de su habilidad de poner en duda la llamada 'realidad objetiva', de subvertir $-\mathrm{O}$ 'descentrar' - la autoridad, de borrar fronteras entre la 'vida' y el 'arte', de hacer desaparecer al autor. Bien. Pero si es exactamente lo que hace Cervantes a principios del siglo XVII, ¿no sería todo esto lo más antiguo y más típico de la novela?

En el prólogo de la primera parte de su novela, Cervantes cita una serie de metáforas tradicionales y bien conocidas: EL LIBRO ES HIJO DEL ENTENDIMIENTO ${ }^{5}$, El AUTOR ES PADRE DEL LIBRO, El LIBRO ES HIJO DEL AUTOR, $\mathrm{y}$ ESCRIBIR UN LIBRO ES ENGENDRAR UN HIJO (I, prólogo, p. 95) ${ }^{6}$. Cervantes insiste en estas ideas diciendo que "cada cosa engendra su semejante", que el "mal cultivado ingenio mío" ha engendrado "un hijo seco, avellanado, antojadizo y lleno de pensamientos varios y nunca imaginados de otro alguno" (es decir, el hijo se parece a su padre), lo que parece indicar que aquí tenemos un ejemplo de un escritor muy consciente de su poder creativo, orgulloso de ser autor de su libro. Por eso nos sorprende cuando escribe que "yo, aunque parezco padre [autor], soy padrastro de don Quijote".

${ }^{5}$ Sigo la práctica de George Lakoff y Mark Johnson, quienes en su libro fundamental, Metaphors We Live By (University of Chicago Press, 1980; Metáforas de la vida cotidiana), suelen indicar las metáforas con el uso de mayúsculas pequeñas.

${ }^{6}$ Cito siempre por la edición revisada y actualizada de John Jay Allen, 25a ed. (Madrid: Cátedra, 2005), indicando parte, capítulo, y página. 
Como la metáfora El AUTOR ES PADRASTRO DEL LIBRO no es nada común, el lector no sabe entender esta afirmación. ¿Otra persona es padre (autor) del libro? Entonces, ¿cuál es la relación entre Cervantes y el libro? ¿Qué significa ser "padrastro" de un libro?

La mayoría de lo que queda del prólogo consiste en una conversación entre Cervantes y un amigo suyo que le ayuda a escribir el prólogo (el prólogo del primer Quijote es, en efecto, un metaprólogo, un prólogo sobre el arte de escribir un prólogo). Pero, durante esta supuesta conversación, Cervantes nos da una pista para descifrar la enigmática referencia al "padrastro" cuando le dice a su amigo que "yo determino que el señor don Quijote se quede sepultado en sus archivos en la Mancha" (p. 97). La manera más fácil y directa de entender esta frase, y el modo en que la mayoría de los lectores han querido entenderla, es que Cervantes nos está diciendo que él, personalmente, no ha inventado (creado, engendrado) la historia de don Quijote, sino que ha existido históricamente este hombre y que otros autores han escrito documentos sobre él, que estos documentos existen en unos archivos que se encuentran en la Mancha, y que él, Cervantes padrastro, ha estudiado (recopilado, editado) estos documentos para escribir su versión de la historia de don Quijote. No hay forma de leer el prólogo sin reconocer que Cervantes se contradice, afirmando que es padre y al mismo tiempo que no es padre del hijo que es el libro.

Así que, según esta segunda versión del asunto, estos historiadores son los auténticos "padres" de don Quijote, y Cervantes, que ha recibido la sustancia de la historia de segunda mano, no hace más que editar esta obra preexistente para presentarla al público. (Y, si queremos continuar con la serie de metáforas ya citadas, tampoco son "padres" estos anónimos historiadores, porque, como dice don Quijote mismo, "cada uno es hijo de sus obras" [I, 4, p. 138]. En este caso la metáfora es que LAS OBRAS DE UNO SON SU PADRE O que CADA PERSONA SE ENGENDRA A Sí MISMA POR MEDIO DE SUS OBRAS, es decir, que LAS OBRAS SON PADRE DE UNA PERSONA - lo que sugiere que don Quijote, por medio de sus obras, es su propio padre. Pero dejemos aquí esta serie de metáforas, porque si seguimos este sendero nos apartaremos de nuestra propia meta, que es la autoría de la novela [y sí, soy muy consciente de la metáfora que implica esta última oración — INVESTIGAR UN ASUNTO ES SEGUIR UN SENDERO HACIA UNA META].)

Cervantes es, de esta manera, "padrastro" de la historia que vamos a leer y, por eso, no es responsable de la autenticidad del texto. En los primeros capítulos, Cervantes sigue insistiendo en que no es el autor original de la historia: "que en esto hay alguna diferencia en los autores que deste caso escriben" (I, 1, p. 114); y "Autores hay que dicen que la primera aventura que le avino fue la del Puerto Lápice; otros dicen que la de los molinos de viento; pero lo que yo he podido averiguar en este caso, y lo que he hallado 
escrito en los anales de la Mancha es que ..." (I, 2, p. 122). Pero justamente cuando el lector está empezando a sentirse cómodo con la idea de que Cervantes edita (es decir, en efecto, con un guiño del ojo, que pretende editar) un texto histórico, compuesto (y no debemos olvidarnos de la portada del libro donde se lee "El Ingenioso Hidalgo Don Quijote de la Mancha / compuesto por Miguel de Cervantes") originalmente por otros autores, llegamos al final del capítulo 8, la batalla entre don Quijote y el valiente vizcaíno, donde leemos lo siguiente:

Pero el daño de todo esto que en este punto y término deja pendiente el autor desta historia esta batalla, disculpándose que no halló más escrito destas hazañas de don Quijote de las que deja referidas. Bien es verdad que el segundo autor desta obra no quiso creer que tan curiosa historia estuviese entregada a las leyes del olvido, no que hubiesen sido tan poco curiosos los ingenios de la Mancha, que no tuviesen en sus archivos o en sus escritorios algunos papeles que deste famoso caballero tratasen; y así, con esta imaginación, no se desesperó de hallar el fin desta apacible historia, el cual, siéndole el cielo favorable, le halló del modo que se contará en la segunda parte ${ }^{7}$. (I, 8, p. 175; énfasis mío.)

Éste es el pasaje más discutido entre los que han escrito sobre la estructura narrativa de la novela. ¿Quiénes son este "autor" y este "segundo autor"? ¿Historiador, editor, Cervantes, narrador anónimo, supernarrador? No quiero entrar aquí en el laberinto narratológico (otra metáfora: EL TEXTO DE LA NOVELA ES UN LABERINTO) de discutir en detalle cómo llegamos a entender estos términos; lo he hecho en otras ocasiones, a las que remito al lector ${ }^{8}$. Baste decir que entiendo que el "autor desta historia" es uno de los historiadores cuyas obras se encuentran en los archivos de la Mancha cuyas fuentes históricas se agotaron en este punto, y que "el segundo autor" es el "padrastro" Cervantes, que investiga los textos históricos archivados en la Mancha, y que es editor del texto que estamos leyendo.

El capítulo siguiente empieza con la búsqueda y hallazgo del manuscrito definitivo que va a servir como base, o fuente, de (casi) todo el resto de la historia. Encontrándose un día en el Alcaná de Toledo (barrio mercantil de la judería), Cervantes se topa con un muchacho que quiere vender

\footnotetext{
${ }^{7}$ Cervantes divide el Quijote de 1605 en cuatro "partes", técnica que abandona en la Segunda Parte de la novela, el Quijote de 1615.

${ }^{8}$ Véanse Howard Mancing, "Cervantes as Author of Don Quijote" (en Cervantes, Vol. $23 \mathrm{~N}^{\circ}$ 1, 2003); y "Response to 'On Narration and Theory" (en Cervantes, Vol. $24 \mathrm{~N}^{\mathrm{o}} 2$ 2, 2005). Para otra manera radicalmente diferente de entender la estructura narrativa del Quijote, véanse James A. Parr, "Don Quixote": An Anatomy of Subversive Discourse (Neewark, De: Juan de la Cuesta, 1988); y "On Narration and Theory" (en Cervantes, Vol. $24 \mathrm{~N}^{\circ}$ 2, 2005).
} 
unos cartapacios escritos en árabe. Curioso, Cervantes toma unas hojas de este manuscrito, las hace traducir al castellano, y se asombra cuando se entera de que se trata de una obra larga que lleva el título de Historia de don Quijote de la Mancha, escrita por Cide Hamete Benengeli, historiador arábigo (I, 9, p. 180). Cervantes paga a un morisco aljamiado (que habla y entiende el árabe y el castellano) para que traduzca la obra, que él (Cervantes) luego edita para el lector. Con este descubrimiento, tenemos la estructura que va a regir durante el resto de la obra: 1) actúan don Quijote y Sancho, 2) escribe su historia Cide Hamete Benengeli, 3) la traduce al castellano el morisco, y 4) edita Cervantes la versión que leemos. Cide Hamete es, así, el definitivo "padre" (autor) de la historia y Cervantes es el "padrastro" (editor). El mayor problema que causa todo esto es que tenemos una "verdadera historia" escrita por un arábigo, "siendo muy propio de los de aquella nación ser mentirosos" (I, 9, p. 182): una verdadera historia escrita por un mentiroso.

De esta ingeniosa manera, Cervantes se distancia de su texto, se contradice, niega (al mismo tiempo que afirma) su autoría de la obra, y pone en duda su autenticidad. Así, Cervantes - autor, editor, padre, padrastro, mago, brujo - crea el primer "embrujo" del Quijote. ¿Qué cosa más natural que una larga historia de embrujos del Quijote si el autor original nos ha enseñado la manera de hacerlo?

\section{El embrujo de la novela}

Ha escrito el crítico norteamericano de literatura comparada, Robert Alter, que:

The novel begins out of an erosion of belief in the authority of the written word and it begins with Cervantes. It fittingly takes as the initial target of its literary critique the first genre to have enjoyed popular success because of the printing press - the Renaissance chivalric romance. Although novelists were by no means the first writers to recognize clearly the fictional status of fictions, I think they were the first - and Cervantes of course the first among them - to see in the mere fictionality of fictions the key to the predicament of a whole culture, and to use this awareness centrally in creating new fictions of their own ${ }^{9}$.

9 "La novela empieza con una erosión de la creencia en la autoridad de la palabra escrita y empieza con Cervantes. Toma, apropiadamente, como primer blanco de su crítica literaria el primer género que haya gozado de un éxito popular a causa de la imprenta - los libros de caballerías. Aunque los novelistas no eran los primeros en reconocer claramente el estado ficticio de las ficciones, creo que eran los primeros -y Cervantes el primero de entre ellos - que vieron en la misma ficcionalidad de las ficciones 
Si Alter tiene razón, y creo que la tiene, la novela como género no es más que un gran embrujo. Según M. M. Bakhtin, la novela emerge en el Renacimiento europeo con las obras de Rabelais y Cervantes (y, diría yo, con La Celestina y Lazarillo de Tormes), una época singular en la que se reúnen por primera vez todas las condiciones que hacen posible este nuevo género, el único que no nace en el anonimato y en la tradición oral de la antigüedad, como la lírica, la épica y el drama: la filosofía (una visión completa del mundo después del "descubrimiento" por los europeos del "resto" del mundo; una orientación horizontal $-\mathrm{y}$ no vertical, como en el medioevo- en el espacio y el tiempo; y el presente abierto), el lenguaje (la diversidad del habla; el mundo galileo de lenguas, la poliglosia, la heteroglosia), y la cultura (la risa, el carnaval) ${ }^{10}$.

Muchos críticos y teóricos anglo-americanos de la novela han tenido otro concepto muy diferente de lo que es este género. En su libro The Great Tradition (London: Chato and Windus, 1948; La gran tradición) W. F. Leavis describe el tipo de novela que él considera más fundamental y más típico. Se trata de obras cuidadosamente estructuradas, serias, sutilmente irónicas y realistas: las novelas de Jane Austen, George Eliot, Henry James, Joseph Conrad, y algunos otros. Éstas son las novelas que menos se parecen al Quijote; les falta la comedia y la risa abiertas, la exuberancia, el tema de la realidad y la ficción, y la técnica narrativa auto-reflexiva que hemos discutido más arriba ${ }^{11}$. Si el Quijote, según esta teoría, es una novela, tiene que ser algún tipo de novela inferior a la supuesta gran tradición.

Ian Watt ha escrito, tal vez, el libro más admirado, más imitado y de más influencia de la historia de la crítica anglo-americana sobre la novela: The Rise of the Novel (University of California Press, 1957; El auge de la novela). Según Watt, la novela aparece por primera vez en la Inglaterra del siglo XVIII a causa de ciertas condiciones culturales: sobre todo el protestantismo y el capitalismo. Toda ficción que antecede este siglo es algo menos que una "novela", en el sentido moderno de este concepto genérico. Watt apenas se refiere, de pasada, al Quijote en su libro, y no se le ocurre buscar la novela en una cultura precapitalista y católica como la España de los siglos XVI y XVII. Los teóricos, críticos e historiadores de la novela que han seguido a Watt - y hay por lo menos medio centenar de ellos-o

la llave para el apuro de toda una cultura y que usaron esta conciencia de una manera central en la creación de sus propias ficciones" (traducción mía); Robert Alter, Partial Magic: The Novel as a Self-Conscious Genre (University of California Press, 1975), p. 3.

${ }^{10} \mathrm{La}$ teoría de la novela que ha desarrollado Bakhtin en pasajes de varios libros se ve mejor en M. M. Bakhtin, The Dialogic Imagination: Four Essays, editado por Michael Holquist y traducción de Caryl Emerson y M. Holquist (University of Texas Press, 1981).

${ }^{11}$ Sin embargo, véanse los comentarios sobre estos autores en Howard Mancing, The Cervantes Encyclopedia, 2 vols., op. cit.; todos han escrito novelas quijotescas. 
ignoran a Cervantes y el Quijote (y a la novela española en general), o consideran al Quijote un tipo de forma primitiva de ficción: un anti-romance (en inglés se distingue entre romance ${ }^{12}$, una forma primitiva y romántica de ficción, tal como la novela antigua de aventuras como la Historia etiópica del griego Heliodoro o el libro de caballerías como Amadís de Gaula, y novela, la forma más moderna, más realista), una mera sátira, un mero romance picaresco (se considera la picaresca una forma primitiva, simplista, satírica de fícción; no conocen la tradición española que comienza con $L a$ zarillo de Tormes), o algo parecido. Para Watt, los primeros novelistas del mundo son Daniel Defoe, Samuel Richardson y Henry Fielding y iqué sorpresa, son todos ingleses!

Es evidente que el concepto de la novela de Alter y Bakhtin (y Walter L. Reed ${ }^{13}$, entre otros) nada tiene que ver con la tradición chauvinista y errónea anglo-americana. Quien conoce el Quijote sabe que es una novela en el más completo sentido de la palabra. Para Bakhtin no hay grandeza sin risa, y, para él, el Quijote es "the classic and purest model of the novel as genre"14. La novela nace riéndose —riéndose de sí misma, burlándose de sí misma, poniendo en duda su propia autenticidad; la novela es, y siempre ha sido, un embrujo.

\section{El embrujo del Quijote, otra vez}

La película de Chumilla y de "El Brujo", "El embrujo del Quijote", no es más que el último ejemplar de una larguísima tradición — de exactamente cuatro siglos - que nace con Cervantes. El filme tiene la posibilidad de destacar dentro de la larga serie de obras cinematográficas relacionadas con la novela de Cervantes. Ha habido más de 150 películas inspiradas en el Quijote ${ }^{15}$, la mayoría de las cuales o tratan de presentar "toda" la historia de las aventuras de don Quijote y Sancho o se basan en un episodio o una

12 En español, el vocablo romance se usa para referirse a un tipo de poesía narrativa, lo que en inglés se llama ballad, y por eso no puede usarse con referencia a una narrativa en prosa como en otras lenguas europeas: roman en francés, romanzo en italiano, y Roman en alemán.

${ }^{13}$ Véase el libro importante de Walter L. Reed, An Exemplary History of the Novel (University of Chicago Press, 1981). Para Reed, la novela comienza en España con la novela picaresca y el Quijote, los dos pilares sobre los que se construye la novela europea.

14 "[E]1 modelo clásico y más puro de la novela como género" (traducción mía); M. M. Bakhtin, The Dialogic Imagination, op. cit., p. 324.

${ }^{15}$ Para la filmografía quijotesca, consúltense Miguel Juan Payán (ed.): El "Quijote" en el cine (Madrid: Ediciones Jaguar, 2005); y Alberto Sánchez Millán, "La imagen de don Quijote en el cine" y "Filmografía seleccionada", en Los rostros de Don Quijote: IV Centenario de la Publicación de su Primera Parte, Aurora Egido, ed. (Zaragoza: IberCaja, 2004), pp. 135-158. Estas obras, aunque de las mejores y más recientes al respecto, distan mucho de proveer una historia completa del tema. 
parte de la novela. Es decir, se concentran en la trama, la acción, los personajes, y no en la técnica. He aquí donde "El embrujo del Quijote" pretende ser algo original en la historia de las películas cervantinas. En esta película lo menos importante es tratar de captar a don Quijote cuando ataca los molinos de viento o los rebaños de ovejas y carneros. Lo que quieren hacer en esta obra es captar algo (aunque sólo una pequeña parte) del espíritu metaficticio, la técnica narrativa, la creatividad de Cervantes. Se espera estrenar "El embrujo del Quijote" durante la festival de Almagro en 2006; veremos hasta qué punto los cineastas y los actores logran su propósito ${ }^{16}$.

\section{REFERENCIAS BIBLIOGRÁFICAS}

Alter, Robert: Partial Magic: The Novel as a Self-Conscious Genre. Berkeley: University of California Press, 1975.

Bakhtin, M. M.: The Dialogic Imagination: Four Essays. Michael Holquist (ed.) y Caryl Emerson y M. Holquist (trad.). Austin: University of Texas Press, 1981.

Branston, Julian: The Eternal Quest. London: Scepter, 2003.

Cervantes, Miguel de: El Ingenioso Hidalgo Don Quijote de la Mancha. John Jay Allen (ed.), 2 vols. $25^{\text {a }}$ ed. Madrid: Cátedra, 2005.

Lakoff, George, y Mark Johnson: Metaphors We Live By. Chicago: University of Chicago Press, 1980.

Leavis, F. R.: The Great Tradition: George Eliot, Henry James, Joseph Conrad. London: Chatto and Windus, 1948.

Mancing, Howard: "Response to 'On Narration and Theory". En Cervantes Vol. $24 \mathrm{~N}^{\circ} 2$ (2005): 135-154.

Mancing, Howard: "Cervantes as Author of Don Quijote". En Cervantes Vol. 23 No 1 (2003), 117-140.

Mancing, Howard: The Cervantes Encyclopedia. Westport, CT: Greenwood Press, 2004.

Parr, James A.: "Don Quixote": An Anatomy of Subversive Discourse. Newark, DE: Juan de la Cuesta, 1988.

Parr, James A.: "On Narration and Theory". En Cervantes Vol. 24 № 2 (2005): 117-133.

Payán, Miguel Juan (ed.): El "Quijote" en el cine. Madrid: Ediciones Jaguar, 2005.

Reed, Walter L.: An Exemplary History of the Novel. Chicago: University of Chicago Press, 1981.

Rivas Hernández, Ascención: Lecturas del Quijote (Siglos XVII-XIX). Salamanca: Ediciones Colegio de España, 1998.

Sánchez Millán, Alberto: "La imagen de don Quijote en el cine" y "Filmografía seleccionada". En Aurora Egido (ed.), Los rostros de Don Quijote: IV centenario de la publicación de su primera parte. Zaragoza: IberCaja, 2004.

Watt, Ian: The Rise of the Novel: Studies in Defoe, Richardson, and Fielding. Berkeley: University of California Press, 1957.

${ }^{16}$ Agradezco profundamente a Juan Manuel Chumilla sus comentarios y sugerencias después de haber leído una primera versión de este ensayo. Le agradezco también el haberme ofrecido la oportunidad de ser asesor, con respecto a Cervantes y su novela, de la película. 